\title{
Understanding Purchase Intention in 020 E-Commerce: The Effects of Trust Transfer and Online Contents
}

\section{Xinxiang Zhang ${ }^{1}$ and Taiyue Wang ${ }^{2}$}

1 Zhongnan University of Economics and Law, School of Information and Safety Engineering, Wuhan, China, xinxiangzhang@zuel.edu.cn

2 Hubei University of Technology, School of Science, Wuhan, China, wangty6895@126.com

Received 29 August 2019; received in revised form 9 February 2020; accepted 5 May 2020

\begin{abstract}
The purpose of this research is to examine the effects of trust transfer and online contents on purchase intention in the online-to-offline e-commerce. A partial least squares based structural equation model was utilized to test the framework of causality and a series of multivariate analyses of variance were conducted to test the effects of online content size. The partial least squares results indicate that trust transfer from online-to-offline platforms to offline merchants, perceived effectiveness of online product reviews as well as perceived effectiveness of numerical ratings positively influence trust in merchants directly and purchase intention indirectly, while perceived effectiveness of online production descriptions shows no significant effect. The multivariate analyses of variance results confirm the positive effects of review number and picture number on customer trust toward merchants and purchase intention. The multivariate analyses of variance results also support the positive effects of review length when a merchant has a high review balance. This research contributes to e-commerce and behavior literature by investigating how trust transfer and online contents engage customers and induce their purchase behaviors in online-to-offline commerce. It also assists leading a better online-to-offline outcome for online-to-offline platforms and offline merchants in the highly competitive online-to-offline markets.
\end{abstract}

Keywords: Online-to-offline e-commerce, Purchase intention, Trust transfer, Online contents, Trust 


\section{Introduction}

Online to offline $(\mathrm{O} 2 \mathrm{O})$ e-commerce is one trend among e-business models [48]. This commerce model tries to attract customers from surfing Internet to experience offline consumption in physical stores [5]. In contrast to traditional ecommerce models that focus on shifting customer shopping from offline to online environment, O2O commerce aims to integrate online platform with offline sales [31]. Owing to the rapid development of modern information technology and its offspring (e.g., Web2.0, smart phones, mobile APPs, etc.) as well as exponential growth of social media, this commerce model is rising quickly in recent years and has covered all e-commerce platforms that focus on travel, catering, transportation, and house. According to a report released by iResearch (2017), China's O2O market size amounted to 978 billion RMB at the end of 2017, with an increase of $46.8 \%$ from 2016 . Driven by the huge profit potential, more and more merchants in China are rushing in the $\mathrm{O} 2 \mathrm{O}$ business. Consequently, attracting customers to purchase is increasingly difficult in this crowded market and thus requires more research attention.

Feedbacks from the $\mathrm{O} 2 \mathrm{O}$ markets show that customers' engagements in purchase depend heavily on whether they can get the expected products from offline merchants. However, information asymmetry, trust fraud, uncertainty, and other transaction risks are common in the $\mathrm{O} 2 \mathrm{O}$ commerce context, which discontent customers and make them hesitant in making purchase decisions [54]. Trust is "the willingness of a party (trustor) to be vulnerable to the actions of another party (trustee) based on the expectation that the other will perform a particular action important to the trustor" [37]. Trust can alleviate customers' perceived risks and promote their purchase intention toward online shopping [25], [62]. For the flourish of $\mathrm{O} 2 \mathrm{O}$ commerce, therefore, it is critical to establish customer trust so that customers can be transferred from curious observers to ones who are willing to transit with offline merchants. Furthermore, O2O ecommerce is quite different from traditional e-commerce where customers can easily return or change products/services. Customers in $\mathrm{O} 2 \mathrm{O}$ commerce must experience offline consumption and cannot easily return or change the products/services, resulting in more cautious in making purchase. In this respect, to induce offline purchase, merchants in $\mathrm{O} 2 \mathrm{O}$ commerce face more difficulties and thus must place more effort into building up trust among customers.

O2O commerce offers merchant opportunities to touch as many customers as possible by offering social media enabled platforms [7]. If customers want to transit with an offline merchant, they need visit a specific O2O platform on which the merchant taps. In reality, customers generally start $\mathrm{O} 2 \mathrm{O}$ transaction from browsing a specific platform, and then filter merchants' products/services online and finally make a purchase decision [13]. Only when customers trust $\mathrm{O} 2 \mathrm{O}$ platforms can they trust offline merchants and then be induced to real-world stores [57]. Following this logic, we infer that trust can be transferred from $\mathrm{O} 2 \mathrm{O}$ platforms to offline merchants, which in turn affects customers' purchase intention. Although previous studies have examined trust transfer across channels, such as from offline vendor to web vendor [30] or from web vendor to mobile vendor [33], trust transfer across online platforms and offline merchants remains a less investigated area.

Besides the web transaction medium, $\mathrm{O} 2 \mathrm{O}$ commerce offers merchants opportunities to influence customers acquired online by stimulating online content generation about the merchants' products/services [43]. Online contents include feedback product reviews, feedback numerical ratings, and product descriptions. Customers generate product reviews and numerical ratings, while merchants post product descriptions. Online contents not only develop knowledge and awareness about offline products/services for prospective customers [39], but also deliver merchants' reputation information [44]. As such, online contents represent affective signals provided to help build up trust in merchants and foster shopping intention. Unfortunately, three main trust fraud problems exist in China's e-commerce markets (including $\mathrm{O} 2 \mathrm{O}$ commerce): feedback under-provision, dishonest report, and negative review reluctance [8]. Merchants also have strong incentives to post positive information online [39]. As a result, positive arguments generally dominate in current online content settings [13]. Therefore, the more accurate comment is that perceived quality of online content serves as reliable affective signal to influence consumers' trust beliefs toward the merchants on board the $\mathrm{O} 2 \mathrm{O}$ platform, which further influences their purchase intention. In addition to the quality of online contents, the quantity of online contents also affects customer attitude and shopping decision. For instance, Ye, Law, Gu and Chen [58] confirm that the total number of online reviews demonstrates positive marketing effects. Zhang, Zhao, Cheung and Lee [59] find that perceived quantity of reviews has a positive effect on behavioral intention. Admittedly, prior research has confirmed that user-provided online contents are one of the most influential factors affecting consumers' purchase decisions [13], [40]. Nevertheless, the underlying mechanism by which online content related variables affects purchase intention is not fully understood. How these different variables affect customer trust toward merchants is still to be seen. The terms product reviews and numerical ratings are seen to be interchangeably used in research [2]. In fact, the two terms represent different online content related variables that have different effects on trust in merchants and purchase intention [42]. The effects of merchant-provided online contents are found infrequently in e-commerce analyzed. Additionally, few studies consider review quantity and review quality simultaneously when examining their impacts on trust in merchants and purchase intention.

To leverage these opportunities, the present study aims to understand customer purchase intention in the $\mathrm{O} 2 \mathrm{O}$ commerce context by examining the effects of trust transfer and online contents in detail. Specifically, this study attempts to explore three main questions: (1) How does trust transfer from O2O platforms to offline merchants drive purchase intention generation? (2) How does perceived quality of online contents influence trust in merchant directly 
and purchase intention indirectly? (3) Which indexes of online content quantity affect trust in merchant as well as purchase intention?

We expect that this study can contribute to three distinct literature streams. First, we examine the $\mathrm{O} 2 \mathrm{O}$ e-commerce, a commerce model that is receiving increasing research attention. Second, we explore the trust transfer from $\mathrm{O} 2 \mathrm{O}$ platforms to offline merchants and its effect on purchase intention, a trust transfer mechanism is fundamentally different from that in previous literatures. Third, we investigate the effects of online contents from two important dimensions, namely content quality and content quantity. In addition, we extend extant literature by examining not only userprovided reviews, but also merchant-provided product descriptions. We also distinguish the two words product reviews and numerical ratings. Meanwhile, we enrich extant literature by detailing the variables measuring online content quantity (content size). This study also hopes to lead a better $\mathrm{O} 2 \mathrm{O}$ outcome for $\mathrm{O} 2 \mathrm{O}$ platforms and offline merchants in the highly competitive $\mathrm{O} 2 \mathrm{O}$ markets.

\section{Concept Framework and Theoretical Foundations}

We provide the theoretical foundations of this study by reviewing some relevant literatures in this section. Specifically, we discuss the main concepts including $\mathrm{O} 2 \mathrm{O}$ commerce, trust transfer, and online contents.

\subsection{Commerce}

O2O commerce refers to "services that match providers to consumers through an Internet-based platform or smartphone application" [21]. As an upgrade of traditional e-commerce models, it completely changes the competition situation in traditional markets [23]. A core platform that connects everything delivers intangible product/service information to users [21]. Offline merchants launched on the platform leverage the merchant-provided information and customer-posted contents to engage prospective customers and induce their offline purchase [43]. O2O platforms and offline merchants do not fight with each other, but work together to serve consumers [43]. By doing this, O2O commerce grows business opportunities for traditional industry as well as improves feeling and value of customer experience.

$\mathrm{O} 2 \mathrm{O}$ business model can be performed as online to offline or offline to online commerce [21]. From a customer perspective, the former model means researching products/services online first and then experiencing them in physical stores offline. The later model means visiting physical store first and then getting virtual services online [49]. From a firm perspective, the former model means "find customers online and bring them into real-world stores" [46]. The later model means exhibiting products/services offline and meeting customers' spontaneous needs online [21]. In reality, most customers carry out extensive information searches online first and then purchase products/services at the realworld stores [13]. In line with this dominated $\mathrm{O} 2 \mathrm{O}$ commerce direction, this study focuses on the online to offline ecommerce.

\subsection{Trust Transfer}

Trust transfer is "a cognitive process that may arise from one familiar context to another new context or from one trusted entity to another unknown entity" [33]. Three actors are involved in the trust transfer process, that is, the trustor, the trustee, and a third entity [50]. The trustor is an individual who judges whether to trust others; the trustee is another individual who is assessed by the trustor based on his/her trustworthiness, and the third entity act as the broker in the trust transfer process [9]. The underlying logic of trust transfer mechanism is that "when the trustor trusts in the third person and there is a close relationship between the trustee and the third person, the trustor's trust in the third person will be transferred to the trustee" [50]. Here, the third entity, the familiar context or trusted entity is called as the source of trust transfer and the trustee, the new context or unknown entity, is called as the target of trust transfer [50], [61]. Perceived relationship between the trustee and trust source plays a crucial role in the trust transfer and trust formation process [9], [34]. There are two main types of relationship band linking trusted target and trust source namely similarity and business tie [47], [50]. Similarity "captures the internal relationship between source and target, such that they share certain same features which make people have same perception about them" [50]. Business ties "capture the external relationship between source and target, such that they may not be same in nature but share certain external cues" [50].

E-commerce research has examined four types of trust transfer process (TTP) [30]. The two intra-channel trust transfer processes (offline to offline TTP and online to online TTP) rely perceived similarity to link two similar channels, while the other two inter-channel trust transfer processes (offline to online TTP and online to offline TTP) rely business tie to link online and offline channels. Since the intra-channel trust transfers have no relationship with the current research, we do not consider them in this study. The existing inter-channel trust transfer literature focuses on the retail industry, in which the online and offline businesses are dual-channel competitive businesses, namely the competition between online stores and traditional stores [7]. Online stores and traditional stores are operated by the same business entities. Thus, online trust and offline trust involves only one trustee (vendor). The two types of trust are in parallel and can function independently. Trust transfer in $\mathrm{O} 2 \mathrm{O}$ e-commerce is inherently different from the above inter-channel trust transfer. First, this trust transfer process involves two different parties (O2O platforms and offline merchants). Second, Trust in platforms and trust in merchants collaborate serially as they function in the same shopping process. 
Considering all these, we draw upon the trust transfer theory to take a new look at the effect of trust transfer from $\mathrm{O} 2 \mathrm{O}$ platforms to offline merchants in our study.

\subsection{Online Contents}

Online contents refer to the information components on an online platform, either textual or graphic [25]. Given the important role of online contents on customer intention and behavior, scholars have paid much attention to it. Overall, their studies generally fall into three main streams. The first stream focuses on the business or information value of online contents [44], the second stream focuses on the trustworthiness of online contents [3], and the third stream studies customers' willingness to contribute online contents based on psychological lens [55].

Besides the research focuses, each stream has its own research methodology. Specifically, text mining, machine learning, and econometric model are mainly used to examine online content related issues. In particular, econometric model is more suitable for predicting perceived trust, sales, and behavior intention. Thus, we use econometric model to understand the effects of online content on purchase intention. Following Bao, Li, Shen and Hou [4], information effectiveness is adopted to measure content quality. This study also denotes content quantity (content size) as another important factor affecting consumer trust and purchase intention. It is worth to mention that online contents consist of use-generated product reviews and numerical ratings as well as merchant-provided product descriptions in the $\mathrm{O} 2 \mathrm{O}$ commerce context. To examine the effects of online content size, we naturally need study several variables, such as the average length of product reviews (textual reviews), the length of product descriptions, the number of product reviews, the number of numerical ratings, and the number of online pictures. In reality, there is no obvious difference in the length among different product descriptions as merchants generally release product information according to specific schemas and norms. Meanwhile, the number of numerical ratings is equal to the number of product reviews for most popular $\mathrm{O} 2 \mathrm{O}$ platforms. Thus, this study uses the total number of product reviews and online pictures as well as the average length of online reviews to measure online content size.

\section{Research Models and Hypotheses}

In this section, we discusses the key components of our research model in great detail. Meanwhile, the expected relationships among these components behind suggested hypotheses are addressed.

\subsection{Effects of Trust Transfer}

Trust can be transferred from a known entity to an unknown entity because of the associations between them [34]. Within the $\mathrm{O} 2 \mathrm{O}$ commerce context, $\mathrm{O} 2 \mathrm{O}$ platform acts as online promotional channels to drive offline sales [43]. Following the trust transfer theory, we argue that customer trust may transfer across O2O platform (the third party) and offline merchants (the trustee) because the interrelationship between them. Indeed, consumers interacting with a web platform make strong inferences about the attributes of the offline merchants from what they experience on the platform. If he/she accrues a favorable experience with the platform, he/she is more likely to trust the merchants tapped on the platform [9]. In addition, popular social media enabled $\mathrm{O} 2 \mathrm{O}$ platforms generally provide fair norms and standards to avoid other members (e.g., merchants on the platforms) to engage in information fraud behaviors. Therefore, when an individual trusts an $\mathrm{O} 2 \mathrm{O}$ platform, he/she will more likely to trust the merchants on the platform, because he/she believes that the merchants would comply with these norms and standards [34]. Furthermore, O2O platforms have the responsibilities to monitor the merchants and ensure the online information reliable. Any dishonest behavior may incur severe punishments, such as monetary penalties, cooperation relationship taken away, or feedback product reviews clearance. In this respect, we can infer that when customers build up strong trust toward an O2O platform, they tend to view any unfamiliar merchant related to the platform as a trustworthy transaction partner because any of its opportunistic behaviors will be punished by the platform. Given this, we hypothesize:

\section{H1: In $\mathrm{O} 2 \mathrm{O}$ e-commerce, trust can be transferred from an $\mathrm{O} 2 \mathrm{O}$ platform to the merchants on the platform.}

\subsection{Effects of online contents}

Since the effectiveness and the size of online contents both affect customer attitude and purchase intention and there is no evidence to conclude that they will produce the same effects, we examine their effects separately.

\subsubsection{The Effects of Online Content Effectiveness}

As user-generated commercial content, online product reviews are thought to be more credible and have a more powerful influence on customers' evaluation than the content obtained from other commercial sources (e.g., advertising) [28]. It serve as an affective signal that help customers make more accurate assessment of a merchant's reputation and impact consumers' purchase decisions [44]. As customers' offline experience is likely to be either good or bad, the overall online reviews for any given product or merchant will be predominantly positive or negative. Positive reviews encourage customers to make purchase decisions, whereas negative reviews discourage potential purchasing [44]. A considerable amount of literatures have suggested that negative reviews are more influential, more persuasive, and 
more difficult to resist than positive reviews [6]. In order to entice more online purchase, firms have incentives to strategically manufacture positive reviews for themselves [38]. Driven by material interests, some customers with purchase experience post fake positive reviews. Worrying about harassment and violent reprisals from merchants, other customers give up posting negative reviews. As a result, online reviews are predominantly positive on most web platforms [13]. However, there is an important impediment to the effectiveness of online reviews in revealing product quality and merchants' reliability, that is, the possible existence of promotional or fake online reviews. Fortunately, online reviews have an objective existence, but perceiving online reviews is a subjective and self-defense process for online customers. Only when customers perceive the online product reviews to be effective, they would then build trust in offline merchants. Moreover, no matter how many positive product reviews a customer has received about the merchant's products/services, without sufficient evidences and related information contained to reflect the merchant's reputation, such reviews are unlikely to lead to a certain trust level. $\mathrm{O} 2 \mathrm{O}$ commerce puts much emphasis on online reviews to increase offline sales [43]. Based on the above discussion, we hypothesize:

H2a: In O2O e-commerce, perceived effectiveness of online product reviews is positively associated with trust toward an unfamiliar offline merchant.

As the core of online reputation system, numerical ratings are acting as another user-generated affective signal to manage trust among customers at the age of Internet [15]. Due to the development of online rating systems, feedback ratings appear to increasingly inspire prospective customers to research the merchants' trustworthiness and to base their decision-making on the judgments given by fellow customers [22]. Any customer can offer feedback ratings to the merchant on its joining $\mathrm{O} 2 \mathrm{O}$ platform after experiencing offline consumption. A positive rating heightens a merchant's rating score, while a negative rating lowers his/her rating score [60]. The higher the rating score, the more reliable the merchant will be believed to be [60]. Usually the following customers prefer the higher rated merchants than the low rated ones [15]. To upgrade trust level and attract more customers, merchants also have strong intention to manipulate trust by purchasing or exchanging positive feedback ratings [22], [60]. On the other side, some customers give unreasonable ratings due to their bad judgment or give highest/lowest ratings to misguide customer choices on purpose [15]. Even if there were neither trust frauds nor noisy ratings, the current 5 star online numerical rating systems still cannot truly reflect customers' opinion about merchants' trustworthiness [18]. Additionally, few consumers leave feedback ratings after experiencing services offline; after a certain period of time, the system generates positive ratings by default [8]. Since it is very easy for merchants to make themselves look trustworthy online, customers have already doubted about the effectiveness of the current feedback rating system in $\mathrm{O} 2 \mathrm{O}$ commerce. Similar to online product reviews, feedback numerical ratings have an objective existence, but perceiving feedback ratings is also a subjective and self-defense process. Only when potential customers perceive that the feedback ratings can provide an objective rating of a merchant's past behaviors, and allow them to assess whether the merchant's trustworthiness meet their own trust expectations, they would then build up trust toward the merchant. Accordingly, we hypothesize:

H2b: In $\mathrm{O} 2 \mathrm{O}$ e-commerce, perceived effectiveness of feedback numerical ratings is positively associated with trust toward an unfamiliar offline merchant.

Generally, offline merchants are allowed to upload texts/images/videos to their joining $\mathrm{O} 2 \mathrm{O}$ platforms. These product descriptions act as the third important affective signal with which customers easily obtain knowledge about the product features, specifications, instructions, defects, matters needing attention and other aspects [11]. iResearch (2015) reported that $40.6 \%$ of the respondents claimed they had come across fake contents on $\mathrm{O} 2 \mathrm{O}$ platforms, a clear implication that credit fraud commonly exists in current reputation systems. In contrast to product reviews and numerical ratings which are consumer-oriented and subjective, merchant-provided product descriptions is productoriented and may be more objective [39]. The reason is that merchants must comply with the norms and standards set by the $\mathrm{O} 2 \mathrm{O}$ platforms when posting information online. However, in order to make online descriptions attractive, offline merchants have strong incentives to hide the key defects and disadvantages of their products/services and emphasize good aspects [39]. Therefore, the possible existence of deceptive and misleading texts/images/videos is also a serious impediment to the effectiveness of online descriptions in displaying product/service information. Similar to online product reviews, only when a consumer perceives online descriptions to be reliable, accurate, comprehensive, up-todate, and valuable, he/she thus develops trust in the ability, benevolence, and integrity of the offline merchant. Thus, we hypothesize:

H2c: In $\mathrm{O} 2 \mathrm{O}$ e-commerce, perceived effectiveness of online product descriptions is positively associated with trust toward an unfamiliar offline merchant.

\subsubsection{The Effects of Online Content Size}

In the $\mathrm{O} 2 \mathrm{O}$ commerce context, individuals may post product reviews to share their emotions after trading with a merchant offline. If people have extremely satisfied or unsatisfied transaction experience with the merchant, they are more likely to share their positive or negative emotions in detail and, as a result, they post longer reviews online [16]. Longer reviews often present comprehensive information about the merchant. The longer the positive reviews, the more favorable information about that merchant will be exhibited. More favorable reviews result in higher level of customer trust in the target merchants; they also generate a more positive post-exposure attitude and a stronger purchase intention [32]. On the contrary, the longer the negative reviews are, the more defects of merchant-provided product and the more untrustworthiness of the merchant are exposed. Negative information usually decrease the level of trust in target merchants; they also have an unfavorable impact on customers' attitudes, which in turn may deter 
them from purchasing in the future [14]. In a word, review balance (the ratio of positive ratings to negative ratings) moderates the effects of review length on trust in merchants as well as purchase intention.

Although more online contents generally benefit customers with more information, many merchants have hundreds or even thousands of reviews, which make it impossible for customers to read all reviews with patience. A survey by (Site 1) suggested that customers read an average of 7 reviews before trusting a merchant and making purchase decision. Thus, we argue that the top 7 reviews receive more attention and have stronger effects on customers' perceptions and behaviors. Accordingly, we hypothesize:

H3a: The average length of top reviews has a significant effect on customers' trust toward merchants.

H3b: The average length of top reviews has a significant effect on customers' purchase intention.

In the interaction stage, a great number of online reviews available help reduce uncertainty and increase customer trust perception toward online reviews [45]. Kostyra, Reiner, Natter and Klapper [27] also argue that the higher review volume, the more trustworthy review valence becomes; if review volume is low, customers will doubt about the trustworthiness of the review valence. If the level of customers' trust perception is higher, the positive association between review-based online reputation system and its patronages will be strengthened [3]. When customers are in a high helpful reputation condition and more exposed to positive reviews, they have more favorable attitude toward the merchant and stronger purchase intention [17], [56]. In reality, the majority of reviews are positive on current 020 platforms [13]. Following the above logic, we infer that when customers read numerous reviews online, they would be more likely to believe in the trustworthiness of these positive reviews; naturally, they will be more confident about their trust perception toward the merchants. Additionally, the total number of online reviews has a positive relationship with on offline merchant's competitive performance [35]. If customers find merchants have a large number of reviews, they can perceive the popularity of the merchants [59]. Perceived popularity further positively influences customers' decision-makings [40]. In fact, larger number of reviews a merchant receives means higher sales and better brand reputation. Influenced by mass psychology, customers will place purchase confidence in the merchant. As a result, an increase in review number causes an increase in sales. Considering the above discussion, we hypothesize:

H4a: The number of product reviews has a positive effect on customers' trust toward merchants.

H4b: The number of produce reviews has a positive effect on customers' purchase intention.

For experience products such as products in $\mathrm{O} 2 \mathrm{O}$ context, when reviewers post reviews or merchants post product descriptions along with pictures, customers would be more certain of how the products will be compared to when no pictures are posted [51]. Pictures are comparatively more effective in helping customers infer merchants' trustworthiness and attractiveness [29]. When customers view more pictures, they would get richer and more powerful information in showing various aspects and holistic nature of a merchant's product [36]. Since positive feedbacks dominate current $\mathrm{O} 2 \mathrm{O}$ reputation system, this information increases the level of attractiveness. An attractive trustee is perceived as more trustworthy and earns more choices [52]. In addition, more pictures mean high sales and positive reputation as most pictures in $\mathrm{O} 2 \mathrm{O}$ commerce are uploaded by customers. Meanwhile, in the $\mathrm{O} 2 \mathrm{O}$ commerce context, to reduce uncertainty, customers without any first-hand knowledge also tend to follow the majority in making purchase decision. If a great many customers have experienced the products and shared their pleasant experience by posting attractive and intuitive pictures, other prospective customers would likely to believe in the provider and strengthen purchase intention. Based on the above discussion, we hypothesize:

H5a: The total number of online pictures has a positive effect on customers' trust toward merchants.

H5b: The total number of online pictures has a positive effect on customers' purchase intention.

\subsection{Trust and Purchase Intention}

Positive trust attitude toward a vendor helps alleviate perceived transaction risks, which in turn promote transaction in traditional e-commerce [62]. In $\mathrm{O} 2 \mathrm{O}$ commerce, customers' consumption decision largely depends on their perceptions whether offline merchants can provide them with consistent products/services as claimed online. When customers believe that an unfamiliar merchant will behave in a trustworthy and expected way by reading reputation information online, they may generate purchase intention [43]. Therefore, we argue that the relation logic between trust and purchase intention is also applicable to the $\mathrm{O} 2 \mathrm{O}$ commerce model. Accordingly, we hypothesize:

\section{H6: In $\mathrm{O} 2 \mathrm{O}$ e-commerce, trust in merchants is positively associated with purchase intention.}

Combining the effects of trust transfer and online contents on purchase intention in $\mathrm{O} 2 \mathrm{O}$ e-commerce, we present the research model with hypotheses in Figure 1. Additionally, it has been confirmed that trust in $\mathrm{O} 2 \mathrm{O}$ platforms has a direct positive influence on purchase intention [1]. Thus, though the confirmed relationship is not hypothesized, we still include it in Figure. 1 to ensure the model completeness. 


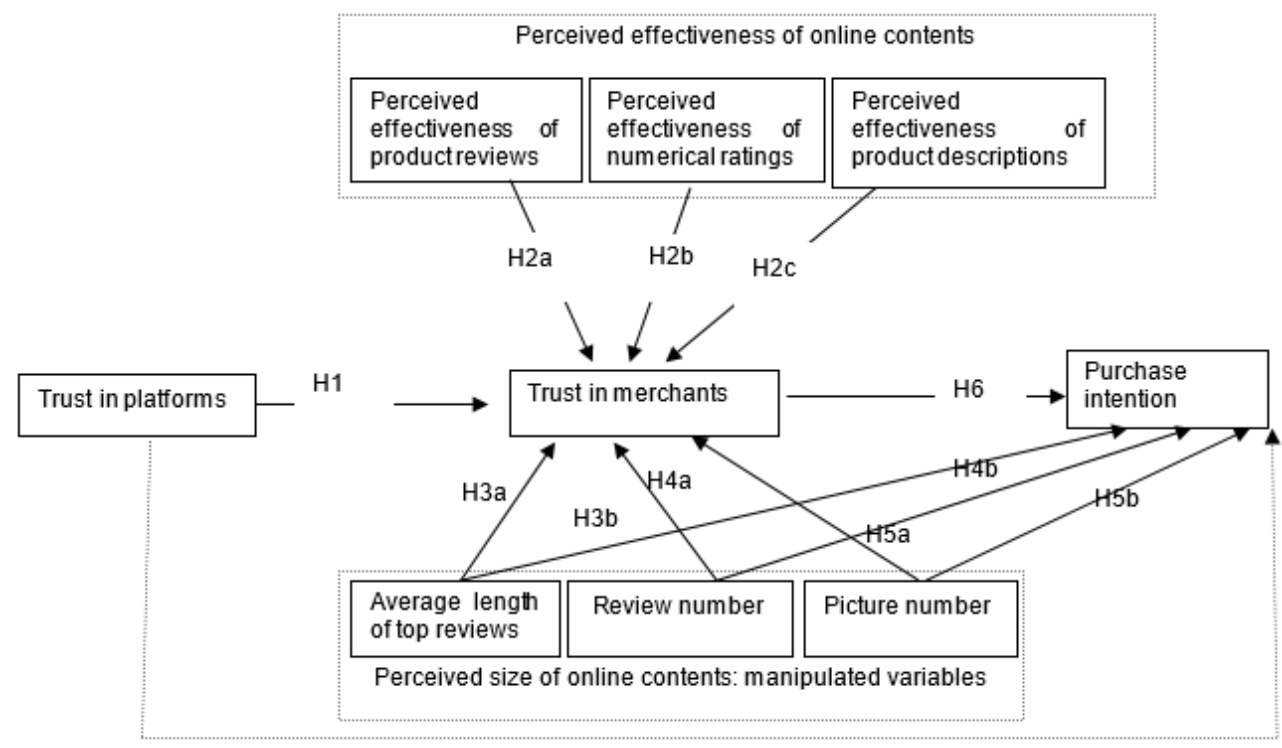

Fiqure 1: Proposed research model

\section{Research Methodology}

This section describes measures, scales adpoted, operational definitions, and data collection.

\subsection{Measurement Development}

We developed a questionnaire survey containing two parts. Part 1 included questions regarding gender, age, education, $\mathrm{O} 2 \mathrm{O}$ transaction experience, the number of user-provided reviews, the number of online pictures, and the average length of top reviews. Part 2 included all of the questions measuring the six constructs on a 7-point Likert scale, as shown in Appendix 1. Wherever possible, we adapted existing validated items from prior literatures. Perceived effectiveness of product reviews (four items) [4], [41], perceived effective of numerical ratings (three items) [4], trust in platforms (three items) [12], trust in merchants (four items) [62] and purchase intention (four items) [24], [62]. As no appropriate scale can be adapted from prior research, we developed new items measuring perceived effectiveness of online product descriptions based on the definition of the construct and focus-group interviews. Meanwhile, taking the items for measuring perceived effective of numerical ratings for references and corresponding to the $\mathrm{O} 2 \mathrm{O}$ practical business, we carefully worded the new item.

Adapting ideas from Park, Lee and Han [40], we classified 10 reviews as a small number of reviews while 100 reviews as a large number of reviews. The same principle was used to classify the picture number. Regarding the average length of top reviews, we conducted data scraping technology to get the general distribution. Data scraped from (Site 2) consisted user reviews on destinations, restaurants, education, etc. The detailed statistics of the dataset showed that average word counts per review were 95.6 Chinese characters. Based on this information, we grouped the top reviews into three subgroups. The top reviews that $50 \%$ of them with word count exceed 150 were viewed as long reviews, while $50 \%$ with word count less than 50 were viewed as short reviews. The others were viewed as medium reviews.

\subsection{Sample and Data Collection}

We collected data through (Site 3), a well-known professional questionnaire website in Chinese language. In order to publicize our online survey, we distributed the URL address of our questionnaire to the most widespread social network sites in China, such as QQ, WeChat, and Sina Weibo. The respondents were asked to visit (Site 2), one of the most popular and largest $\mathrm{O} 2 \mathrm{O}$ platforms in China. After reading the contents online about a specific unfamiliar merchant who operates tourism destination in rural China, they were invited to fill out the questionnaires. To improve the response rate, we awarded respondents with Wechat Red Bags or QQ Red Bags.

In sum, we received 316 responses. After discarding the invalid responses (giving all the items the same value), we ultimately obtained 255 valid samples for data analysis. Among these 255 respondents, $42.19 \%$ were male and 57.81 were female. The respondents were relatively young: $62.89 \%$ aged between 21 and 30, and $26.95 \%$ under 21 . In terms of education, most of the respondents were well educated: $72.46 \%$ had a bachelor's degree, and $19.07 \%$ had a master's degree or higher. The sample represents general customers in China's $\mathrm{O} 2 \mathrm{O}$ market that are quite young but well educated (iResearch, 2017). In addition, the respondents were quite inexperienced, with more than $40 \%$ 
having less than one-year $\mathrm{O} 2 \mathrm{O}$ experience, and more than $30 \%$ using $\mathrm{O} 2 \mathrm{O}$ model less than once within the latest year.

\section{Data Analysis and Results}

Worrying about the possible correlation between online content size and online content effectiveness, meanwhile, to examine the effects of online content size in detail, we examined the two groups of variables separately. The effects of online content size were analyzed using multivariate analyses of variance (MANOVA) tests and the framework of causality among other variables was tested with a PLS-based Structural Equation Modeling (SEM).

\subsection{Measurement Validation}

First, we evaluated the factor reliability and internal-consistency reliability of principal constructs. The values of Cronbach's alpha, as shown in Table 1 , rang from 0.86 to 0.91 , indicating excellent internal-consistency reliability. The composite reliabilities for all the constructs are far above the 0.7 cut-off point, exhibiting adequate construct reliability. Additionally, all items have loadings greater than 0.6. Next, we assessed the convergent and discriminant validity by inspecting the average variance extracted (AVEs) and correlation coefficient. Table 1 indicates that the AVEs fall between 0.7051 and 0.8085 , all above the criterion of 0.5 , demonstrating adequate convergent validity. The discriminant validity was assessed by comparing the square root of each AVE with every possible correlation coefficient among constructs and the result shown in Table 1 was found to be well achieved. Meanwhile, we looked at the cross loadings presented in Table 2; the results indicate that the loading of each indicator on its own construct is greater than its loadings on any other latent constructs, also suggesting that the constructs are distinct.

Given several relatively high correlation coefficients among latent constructs, we performed a multicollinearity test by examining the variance inflation factors (VIFs). There are two types of VIFs: outer VIF and inner VIF. Any VIF value higher than 5.0 implies that potential multicollinearity problem will threat the validity of empirical research [19]. In our study, the highest outer VIF was 2.098 and the highest inner VIF was 2.554, both lower than the cut off level of 5. Thus, we contend that multicollinearity pose no significant threat to our research.

Table 1: Reliability, validity, and correlations for constructs

\begin{tabular}{|c|c|c|c|c|c|c|c|c|c|c|}
\hline Constructs & RSFL & $\alpha$ & CR & AVE & PPR & PNR & PPD & TIP & TIM & $\mathrm{PI}$ \\
\hline $\begin{array}{l}\text { Perceived effectiveness of product } \\
\text { reviews (PPR) }\end{array}$ & $0.80-0.89$ & 0.87 & 0.91 & 0.72 & 0.85 & & & & & \\
\hline $\begin{array}{l}\text { Perceived effectiveness of } \\
\text { numerical ratings (PNR) }\end{array}$ & $0.87-0.93$ & 0.88 & 0.93 & 0.81 & 0.66 & 0.90 & & & & \\
\hline $\begin{array}{l}\text { Perceived effectiveness of online } \\
\text { product descriptions (PPD) }\end{array}$ & $0.82-0.91$ & 0.88 & 0.92 & 0.73 & 0.77 & 0.79 & 0.86 & & & \\
\hline Trust in platforms (TIP) & $0.88-0.91$ & 0.87 & 0.92 & 0.80 & 0.50 & 0.71 & 0.68 & 0.89 & & \\
\hline Trust in merchants (TIM) & $0.83-0.85$ & 0.86 & 0.91 & 0.76 & 0.60 & 0.68 & 0.69 & 0.71 & 0.84 & \\
\hline Purchase intention (PI) & $0.87-0.89$ & 0.91 & 0.931 & 0.78 & 0.62 & 0.70 & 0.76 & 0.72 & 0.67 & 0.88 \\
\hline
\end{tabular}

Notes: RSFL: Range of factor loadings; $\alpha$ : Cronbach's alpha; CR: Composite reliability; AVE: Average variance extracted

Table 2: Loadings and cross-loadings of measurement items

\begin{tabular}{|l|l|l|l|l|l|l|}
\hline & PPR & \multicolumn{1}{|c|}{ PNR } & PPD & TIP & TIM & PI \\
\hline PPR1 & 0.800 & 0.523 & 0.597 & 0.377 & 0.469 & 0.489 \\
\hline PPR2 & 0.891 & 0.583 & 0.665 & 0.439 & 0.540 & 0.515 \\
\hline PPR3 & 0.881 & 0.538 & 0.649 & 0.415 & 0.500 & 0.530 \\
\hline PPR4 & 0.823 & 0.590 & 0.689 & 0.474 & 0.532 & 0.553 \\
\hline PNR1 & 0.574 & 0.870 & 0.708 & 0.580 & 0.595 & 0.618 \\
\hline PNR2 & 0.612 & 0.930 & 0.729 & 0.658 & 0.646 & 0.655 \\
\hline PNR3 & 0.590 & 0.896 & 0.704 & 0.687 & 0.600 & 0.628 \\
\hline PPD1 & 0.660 & 0.668 & 0.817 & 0.530 & 0.552 & 0.573 \\
\hline PPD2 & 0.665 & 0.674 & 0.876 & 0.593 & 0.594 & 0.689 \\
\hline PPD3 & 0.692 & 0.705 & 0.910 & 0.615 & 0.629 & 0.681 \\
\hline PPD4 & 0.607 & 0.670 & 0.816 & 0.597 & 0.569 & 0.640 \\
\hline TIP1 & 0.472 & 0.699 & 0.630 & 0.911 & 0.661 & 0.649 \\
\hline TIP2 & 0.399 & 0.624 & 0.626 & 0.880 & 0.600 & 0.672 \\
\hline TIP3 & 0.473 & 0.584 & 0.573 & 0.885 & 0.626 & 0.606 \\
\hline TIM1 & 0.466 & 0.526 & 0.542 & 0.627 & 0.825 & 0.538 \\
\hline TIM2 & 0.506 & 0.576 & 0.555 & 0.625 & 0.845 & 0.532 \\
\hline TIM3 & 0.549 & 0.611 & 0.640 & 0.601 & 0.853 & 0.637 \\
\hline TIM4 & 0.498 & 0.578 & 0.560 & 0.516 & 0.836 & 0.546 \\
\hline PI1 & 0.525 & 0.656 & 0.681 & 0.637 & 0.607 & 0.869 \\
\hline PI2 & 0.550 & 0.607 & 0.691 & 0.664 & 0.621 & 0.891 \\
\hline PI3 & 0.534 & 0.592 & 0.637 & 0.630 & 0.551 & 0.881 \\
\hline PI4 & 0.563 & 0.632 & 0.657 & 0.608 & 0.592 & 0.891 \\
\hline
\end{tabular}




\subsection{Testing the Structural Model}

After checking validity and reliability, we tested the structural equation model using PLS algorithm. Figure 2 reports the path coefficients along with explanatory power $\left(R^{2}\right)$. The model explains $60.4 \%$ of the variance for trust in merchants, and $57.3 \%$ of the variance for purchase intention. A bootstrapping procedure with 2000 replications was applied to estimate the statistical significance of the regression weights.

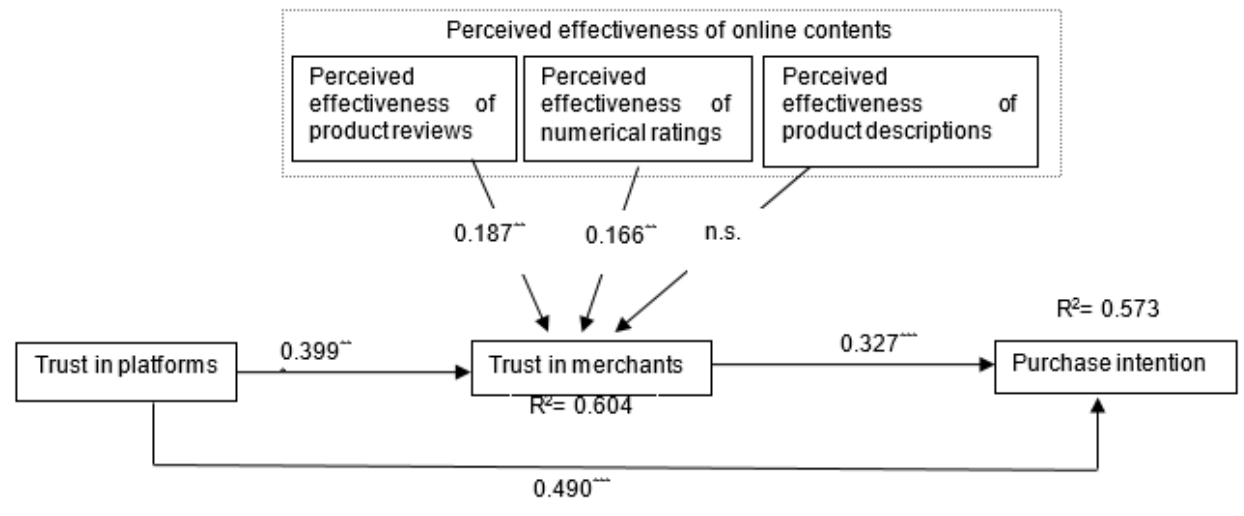

Figure 2. Results of structural model

Notes: ": $p<0.1, "$ : $p<0.05,{ }^{* * *}: p<0.01$.

According to Figure 2, perceived effectiveness of product reviews $(\beta=0.187, p<0.05)$ and numerical ratings $(\beta=0.166$, $p<0.05)$ are important determinants of trust in merchants. By contrast, perceived effectiveness of product reviews acts as a more important precedent. Contrary to our predictions, perceived effectiveness of online product descriptions is found to have no significant predictive power for trust in merchants. These results support $\mathrm{H} 2 \mathrm{a}$ and $\mathrm{H} 2 \mathrm{~b}$, while reject $\mathrm{H} 2 \mathrm{c}$. Regarding the effect of trust transfer, as confirmed, trust in $\mathrm{O} 2 \mathrm{O}$ platforms can been transferred to trust in merchants $(\beta=0.399, p<0.01)$, supporting hypothesis $H 1$. Furthermore, trust in merchants $(\beta=0.327, p<0.01)$ shows strong positive impact on purchase intention, supporting $\mathrm{H} 6$.

\subsection{Testing the Effects of Online Content Size}

We performed several MANOVA analyses to test the hypotheses regarding online content size. Given the high reliability of factor measures, we believed that the factor scores of trust in merchants and purchase intention represented the information contained in the two constructs. Thus, we used SPSS 19 to finish the MANOVA tests and multiple comparisons based on the factor scores.

\subsubsection{Effects of Average Length of Top Reviews}

A MANOVA test shows the effects of review length on trust in merchants and purchase intention are both significant $(F=16.54, d f=2, p=0.00 ; F=23.00, d f=2, p=0.00)$. A Games-Howell test in analysis of variance (ANOVA) further indicates that compared to short reviews, long reviews trigger more trust (mean difference $=1.31, P=0.00$ ) and foster more purchase intention (mean difference $=0.96, p=0.00$ ), as shown in Table 3 . There is also a significant difference between long and medium review lengths regarding trust in merchants and shopping intention. However, significant difference only exists between the effects of medium and short review lengths on trust in merchants but not on purchase intention. These results confirm hypothesis $\mathrm{H} 3 \mathrm{a}$ and $\mathrm{H} 3 \mathrm{~b}$ to some extent.

\subsubsection{Effects of Review Number}

MANOVA findings confirm a significant effect of review number on trust in merchants $(F=51.13, d f=2, p=0.00)$ and purchase intention $(F=61.56, \mathrm{df}=2, \mathrm{p}=0.00)$. The following Games-Howell test indicates that compared to small number of reviews, large and medium number of reviews both result in a higher level of trust in merchants and a more positive attitude toward purchase (see in Table 3). Significant differences also exist between large and medium number of reviews. Therefore, $\mathrm{H} 4 \mathrm{a}$ and $\mathrm{H} 4 \mathrm{~b}$ are supported.

\subsubsection{Effects of Picture Number}

The MANOVA test also suggests a statistically significant picture number effects on trust in merchants $(F=16.45, \mathrm{df}=2$, $\mathrm{p}=0.00$ ) and purchase intention $(\mathrm{F}=25.55, \mathrm{df}=2, \mathrm{p}=0.00)$. The following ANOVA analysis (see in Table 3 ) reveals that customers who have browsed a large number of pictures are more likely to generate trust toward merchants and purchase intention than those who have browsed a medium or small number of pictures. In addition, customers who have browsed a medium number of pictures are also more likely to generate trust and purchase intention than those who have browsed a small number of pictures. Therefore, $\mathrm{H} 5 \mathrm{a}$ and $\mathrm{H} 5 \mathrm{~b}$ are supported. 
Table 3: Multiple comparison of the review lengths, review number and picture number

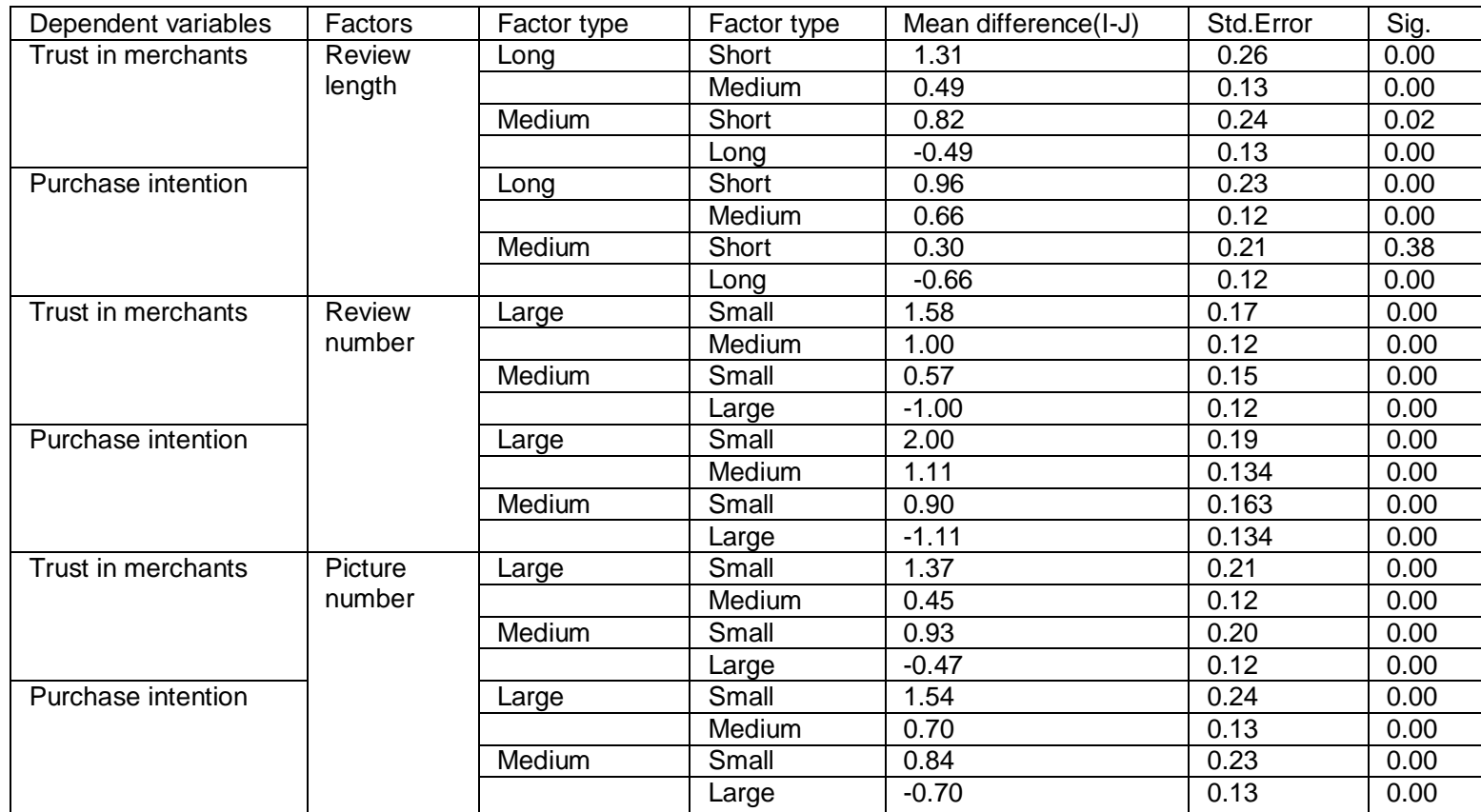

\section{Discussion and Implications}

The major findings are summarized as follows incorporating comparison with extant $\mathrm{B} 2 \mathrm{C} / \mathrm{C} 2 \mathrm{C}$ literatures. Based on the research findings, we present the theoretical and practical implications for $\mathrm{O} 2 \mathrm{O}$ commerce researchers and practitioners.

\subsection{Discussion of Findings}

First, this study suggests trust can be transferred from $\mathrm{O} 2 \mathrm{O}$ platforms to offline merchants, which in turn enhances customer purchase intention. Our result extends prior finding in Chen, Huang, Davison and Hua [9] that positive perception and attitude toward a C2C platform can be automatically transferred to any seller on the platform and then drive offline sale. Meanwhile, the result implies that in a complex system, such as $\mathrm{O} 2 \mathrm{O}$ system, the involved parties are not isolate but interacts with each other. Our study reconfirms the direct effect of trust in platform. It is not very costly and challenging to achieve an adequate system quality website today. Nevertheless, how to provide a reliable and reputable $\mathrm{O} 2 \mathrm{O}$ platform is still need to be considered as trust in platform can affect purchase intention directly and indirectly.

Second, regarding the three proposed compondents of online contents, only perceived effectiveness of product reviews and numerical ratings are found to have significant effects on trust in merchants, perceived effectiveness of online descriptions is found to have not. Our empirical result confirms the conclusion that user-generated reviews at (Site 2) impact customer choice of merchants [53]. In contrast to perceived effectiveness of product reviews, perceived effectiveness of numerical ratings has weaker impact. This finding confirms the argument proposed by Pavlou and Dimoka [42] that text reviews represent a more imperative aspect than crude numerical ratings to faciliate purchase by building customer trust toward offline merchants. A possible explanation is that noisy and biased ratings are widely found in practical web-based rating systems [15]. In addition, the 5 stars rating mechanism in $\mathrm{O} 2 \mathrm{O}$ website is not adequate for filtering out untrusted merchants. Contrary to our expection, perceived effectiveness of online production descriptions does not play a positive role in building trust toward merchants. The plausable explanations may be that (Site 2) pays much attention to stimulating customer review generation, while pays little attention to encouraging merchant descriptions provision. Many merchants on (Site 2), such as farm tourism merchants, upload very simple information or just release operating hours. As a consequence, limited online descriptions are inadequate for building customer trust toward merchants in our context.

Third, our findings suggest that online content size has significant effects on both offline trust and purchase intention. Specifically, long reviews increse more customer trust and purhchase intention than medium and short reviews. This result confirms the fact that positive ratings are much more frequent than negative ratings on the present $\mathrm{O} 2 \mathrm{O}$ platform, and this is also the scenario in rural tourism $\mathrm{O} 2 \mathrm{O}$ business. Meanwhile, our result help understand the positive and statistically significant relationship between average length of reviews and sales at (Site 4) [10]. In accordance with our hypothesis, as the number of review grows, customers are more likely to place confidence on merchants' trustworthiness and more willingness to make purchase decisions. This empirical result offers evidence for the 
suggestion that the effect of review volume on sale is significant and positive for average review rating above a certain anchor point [56]. Regarding the effect of the number of online pictures, the result supports our hypothesis that an increase in picture number would enhance customer trust as well as purchase intention. This result is interesting and extend prior findings that the addition of pictures to textual reviews influences consumer attitude toward merchants and behavioral intention to experience the products/services [26].

\subsection{Implications for Theory}

Although the focus of this study, the determinants of purchase intention is not new to the traditional e-commerce literatures, relevant studies concerning the effects of trust transfer and online contents on purchase intention in the context of $\mathrm{O} 2 \mathrm{O}$ commerce are rare. This study provides a fine-grained insight into purchase intention under the $\mathrm{O} 2 \mathrm{O}$ commerce environment.

First, it extends extant research by employing the trust transfer across two totally different entities in the same transaction process, a trust transfer is quite different from extant inter-channel trust transfer, in which the trustee only shifts from offline vendor to e-vendor or from e-vendor to offline vendor. Up to now, this trust transfer mechanism has received less research attention. More specifically, following the online to offline commerce logic, we focus on the relationship direction trust in platform to trust in merchant, a relationship direction fit common transaction practices in $\mathrm{O} 2 \mathrm{O}$ commerce. Based on trust transfer theory, we confirm that trust can transfer from $\mathrm{O} 2 \mathrm{O}$ platforms to offline merchants.

Second, this study examines the effects of product reviews, numerical ratings, and online product descriptions separately. This extends previous research that view online content as a single cue and pay little attention to the effect of merchant-provided product descriptions. Results confirm that the three components contribute differently to customer trust toward merchants. Though we found insignificant association between perceived effectiveness of online product description and merchant trust building, future research can choose other O2O platforms, for example (Site 5), as research context to investigate the relationship again.

Third, this study investigates the effects of online contents from two important dimensions, namely content effectiveness and content size. Regarding the effects of content size, this study adds to extant literature by examining the effect of picture number on trust in merchants and purchase intention. It also examines the relationship between review length, review number and their dependent variables. Though our datasets support the positive effect of review length, it opens up interesting directions for future research. For example, we can re-examine the negative relationship that an increase in review length can significantly decrease customers' trust toward merchant or purchase intention when the merchant has a low review balance.

Finally, review number or review length is often examined as control variables in SEM models with PLS algorithm. By contrast, MANOVA tests used in this study may produce more detailed and accurate results.

\subsection{Implications for Practice}

With our study, we address several practical implications for practitioners to lead a better O2O outcome in the highly competitive $\mathrm{O} 2 \mathrm{O}$ markets.

First, since trust transfer from $\mathrm{O} 2 \mathrm{O}$ platforms to offline merchants is found to be an important driver of purchase intention in the $\mathrm{O} 2 \mathrm{O}$ commerce context, $\mathrm{O} 2 \mathrm{O}$ platform vendors should set fair norms and standards in their service level agreements for related merchants or fellow customers. The more important work for $\mathrm{O} 2 \mathrm{O}$ platforms is to supervise online content generation. Once dishonest merchants are reported or malicious competitors are detected, O2O platform must punish them severely. On the other side, offline merchants can choose to tap on a reliable and reputable $\mathrm{O} 2 \mathrm{O}$ platform, from which customer trust toward the platform can be transferred. Meanwhile, merchant trust can be built up quickly but at low cost.

Second, the research results confirm that prospective customers use perceived effectiveness of online contents as the major signal to evaluate merchants' trustworthiness. Our results also suggest that potential customers show doubt on online reviews and pay less attention to the feedback ratings. This requires platform providers and computer experts take technical measures (e.g., logistic regression, text mining, social network analysis, etc) to detect and control online review manipulation strategies. At the same time, they should improve present numerical rating mechanism or develop a more scientific, accurate, and effective feedback rating system. Furthermore, designers are recommended to develop a certain kind of prosecution service, which can help customers easily report any user-posted contents that are fraud and fake, or with inappropriate content, irrelevant content, and advertisements.

Third, now that the research validates the effects of online content size on merchant trust and purchase intention. O2O platforms and offline merchants should undertake appropriate promotional endeavors that could motivate consumers to contribute more online reviews and pictures for their $\mathrm{O} 2 \mathrm{O}$ business. For example, coupons, price discounts, free samples, or points are available and effective promotions. 


\subsection{Limitations and Future Research}

This work is not free from limitations. First, although online to offline commerce model is the dominant O2O model, the less frequent but growing $\mathrm{O} 2 \mathrm{O}$ model, called offline to online commerce model is also threatening tradition business. Future research needs to examine purchase intention under this commerce context with a reverse path. Second, other factors such as price and competitive location may also affect customer purchase intention in the O2O commerce [20]. Since it is not appropriate and impossible to include all possible elements in a model for that will make the model to be a pointless ramble, this study only considers the two settings: trust transfer and online content. However, we acknowledge that these critical elements need to be identified and examined in future research. Third, this study focuses on the effects of positive online contents. In fact, negative information may have stronger and more influential effects on customers' purchase decisions. Future research will conduct a quasi-experiential design where participants are assigned to read different online contents and then investigate the different effects of positive, neutral, and negative online contents. Finally, this study selects online tourism as the research context, but the generalization of our findings to other $\mathrm{O} 2 \mathrm{O}$ context (e.g., catering and entertainment) requires additional research. In addition, the effects of online contents may vary according to product types. Thus, the comparation of different types of products (e.g.,destination product, food product and entertainment products) could be an interesting topic in future work.

\section{Conclusion}

Attracting customers is increasingly difficult in the fierce competition $\mathrm{O} 2 \mathrm{O}$ market, and thus to understand the factors facilitating customer engagement is required. This study focuses on how trust transfer and online contents drive purchase in the $\mathrm{O} 2 \mathrm{O}$ commerce context. Based on data collected from 255 samples, we used PLS algorithm and MANOVA analysis to test our research model. The PLS results suggest that trust in $\mathrm{O} 2 \mathrm{O}$ platforms, perceived effectiveness of online product reviews as well as perceived effectiveness of numerical ratings positively affect trust in offline merchants. However, their impacts are found to be different. Trust transfer has the strongest impact, followed by perceived effectiveness of product reviews, and finally perceived effectiveness of numerical ratings. Supprisingly, perceived effectiveness of online production descriptions shows no significant effect. The MANOVA results suggest that online content size has significant influences on both offline trust and purchase intention. Specifically, as the number of review or picture grows, customers would be more likely to trust offline merchants and more willingness to engage in purchase behaviors in the $\mathrm{O} 2 \mathrm{O}$ context. With the findings, we present theoretical implications for $\mathrm{O} 2 \mathrm{O}$ commerce and customer behavior literature. We also address several practical implications for O2O platform providers and offline merchants to build up merchant trust and foster shopping intention.

\section{Acknowledgments}

This work is supported by National Social Science Foundation of China (Grant No:16BGL192) and Hubei Soft Science Research Program (Grant No: 2019ADC149).

\section{Websites List}

Site 1: Brightlocal.com

https://www.brightlocal.com

Site 2: Dianping.com

http://www.dianping.com

Site 3: wenjuan.com

https://www.wenjuan.com

Site 4: Amazon.com

https://www.amazon.com

Site 5: Ctrip.com

https://www.ctrip.com

\section{References}

[1] G. M. Agag and A. A. El-Masry, Why do consumers trust online travel websites? Drivers and outcomes of consumer trust toward online travel websites, Journal of Travel Research, vol. 56, no. 3, pp. 347-369, 2017.

[2] A. Arunkarthi and M. Gandhi, Aspect-based opinion mining from online reviews, Research Journal of Pharmaceutical Biological and Chemical Sciences, vol. 7, no. 3, pp. 494-500, 2016. 
[3] S. Banerjee, S. Bhattacharyya and I. Bose, Whose online reviews to trust? Understanding reviewer trustworthiness and its impact on business, Decision Support Systems, vol. 96, no. 4, pp. 17-26, 2017.

[4] H. Bao, B. Li, J. Shen, and F. Hou, Repurchase intention in Chinese e-marketplace roles of interactivity, Industrial Management \& Data Systems, vol. 116, no. 8, pp. 1759-1778, 2016.

[5] H. M. Cai, S. Luan, L. H. Jiang, N. Shah, R. Farmer, K. M. Chao, and B. Y. Xu, A multi-layer internet of things database schema for online-to-offline systems, International Journal of Distributed Sensor Networks, vol. 12, no. 8, pp. 12, 2016.

[6] L. V. Casaló, C. Flavián, M. Guinalíu, Y. Ekinci, D. Martin, M. Rosenbaum, and S. Ham, Avoiding the dark side of positive online consumer reviews: enhancing reviews' usefulness for high risk-averse travelers, Journal of Business Research, vol. 68, no. 9, pp. 1829-1835, 2015.

[7] Y. W. Chang, P. Y. Hsu and Q. M. Yang, Integration of online and offline channels: A view of O2O commerce, Internet Research, vol. 28, no. 4, pp. 926-945, 2018.

[8] L. Chen, T. Jiang, W. Li, S. Geng, and S. Hussain, Who should pay for online reviews? Design of an online user feedback mechanism, Electronic Commerce Research \& Applications, vol. 23, no. 3, pp. 38-44, 2017.

[9] X. Chen, Q. Huang, R. M. Davison, and Z. Hua, What drives trust transfer? The moderating roles of seller-Specific and general institutional mechanisms, International Journal of Electronic Commerce, vol. 20, no. 2, pp. 261-289, 2015.

[10] J. A. Chevalier and D. Mayzlin, The effect of word of mouth on sales: Online book reviews, Journal of Marketing Research, vol. 43, no. 3, pp. 345-354, 2006.

[11] A. Daiya and S. Roy, User and firm generated content on online social media: A review and research directions, international Journal of Online Marketing, vol. 6, no. 3, pp. 34-49, 2016.

[12] Y. Fang, I. Qureshi, H. Sun, P. Mccole, E. Ramsey, and K. H. Lim, Trust, satisfaction, and online repurchase intention: the moderating role of perceived effectiveness of E-commerce institutional mechanisms, Mis Quarterly, vol. 38, no. 2, pp. 407-427, 2014.

[13] C. Flavián, R. Gurrea and C. Orús, Choice confidence in the webrooming purchase process: The impact of online positive reviews and the motivation to touch, Journal of Consumer Behaviour, vol. 15, no. 5, pp. 459-476, 2016.

[14] K. Floyd, R. Freling, S. Alhoqail, H. Y. Cho, and T. Freling, How online product reviews affect retail sales: A metaanalysis, Journal of Retailing, vol. 90, no. 2, pp. 217-232, 2014.

[15] J. Gao and T. Zhou, Evaluating user reputation in online rating systems via an iterative group-based ranking method, Physica a-Statistical Mechanics and Its Applications, vol. 473, pp. 546-560, 2017

[16] M. Ghasemaghaei, S. P. Eslami, K. Deal, and K. Hassanein, Reviews' length and sentiment as correlates of online reviews' ratings, Internet Research, vol. 28, no. 3, pp. 544-563, 2018.

[17] T. Ghosh, Predicting hotel book intention: The influential role of helpfulness and advocacy of online reviews, Journal of Hospitality Marketing \& Management, vol. 27, no. 3, pp. 299-322, 2018.

[18] G. B. Guo, J. Zhang, D. Thalmann, and N. Yorke-Smith, Leveraging prior ratings for recommender systems in ecommerce, Electronic Commerce Research and Applications, vol. 13, no. 6, pp. 440-455, 2014.

[19] J. F. Hair, G. T. M. Hult, C. M. Ringle, and M. Sarstedt, A Primer on Partial Least Squares Structural Equation Modeling (PLS-SEM), 2nd edition, 2016.

[20] Z. He, T. C. E. Cheng, J. C. Dong, and S. Y. Wang, Evolutionary location and pricing strategies for service merchants in competitive $\mathrm{O} 2 \mathrm{O}$ markets, European Journal of Operational Research, vol. 254, no. 2, pp. 595-609, 2016.

[21] S. Y. Hwang, and S. Kim, Does mIM experience affect satisfaction with and loyalty toward O2O services?, Computers in Human Behavior, vol. 82, no. 3, pp. 70-80, 2018.

[22] O. Ivanova and M. Scholz, How can online marketplaces reduce rating manipulation? A new approach on dynamic aggregation of online ratings, Decision Support Systems, vol. 104, pp. 64-78, 2017.

[23] J. Ji, Z. Zhang and L. Yang, Comparisons of initial carbon allowance allocation rules in an O2O retail supply chain with the cap-and-trade regulation, International Journal of Production Economics, vol. 187, pp. 68-84, 2017.

[24] B. K. Jin, An empirical study on consumer first purchase intention in online shopping: Integrating initial trust and TAM, Electronic Commerce Research, vol. 12, no. 2, pp. 125-150, 2012.

[25] F. P. Karimov, M. Brengman and L. Van Hove, The effect of website design dimensions on initial trust: a synthesis of the empirical literature, Journal of Electronic Commerce Research, vol. 12, no. 4, pp. 272-301, 2011.

[26] M. Kim, J. H. Kim and S. J. Lennon, Online service attributes available on apparel retail web sites: An e-s-qual approach, Journal of Service Theory \& Practice, vol. 16, no. 1, pp. 51-77, 2006.

[27] D. S. Kostyra, J. Reiner, M. Natter, and D. Klapper, Decomposing the effects of online customer reviews on brand, price, and product attributes, International Journal of Research in Marketing, vol. 33, no. 1, pp. 11-26, 2016.

[28] R. N. Laczniak, T. E. Decarlo and S. N. Ramaswami, Consumers' responses to negative word-of-mouth communication: An attribution theory perspective, Journal of Consumer Psychology, vol. 11, no. 1, pp. 57-73, 2001.

[29] E. J. Lee and S. Y. Shin, When do consumers buy online product reviews? Effects of review quality, product type, and reviewer's photo, Computers in Human Behavior, vol. 31, no. 1, pp. 356-366, 2014.

[30] K. C. Lee, I. Kang and D. H. McKnight, Transfer from offline trust to key online perceptions: An empirical study, IEEE Transactions on Engineering Management, vol. 54, no. 4, pp. 729-741, 2007.

[31] H. Li, Q. Shen and Y. Bart, Local Market Characteristics and Online-to-Offline Commerce: An Empirical Analysis of Groupon, Management Science, vol. 64, no. 4, pp. 1860-1878, 2018.

[32] C. A. Lin and X. Xu, Effectiveness of online consumer reviews: The influence of source trustworthiness, valence, reviewer ethnicity and social distance, Internet Research, vol. 27, no. 2, pp. 362-380, 2017. 
[33] J. Lin, Y. Lu, B. Wang, and K. K. Wei, The role of inter-channel trust transfer in establishing mobile commerce trust, Electronic Commerce Research and Applications, vol. 10, no. 6, pp. 615-625, 2011

[34] L. Liu, M. K. O. Lee, R. Liu, and J. Chen, Trust transfer in social media brand communities: The role of consumer engagement, International Journal of Information Management, vol. 41, pp. 1-13, 2018.

[35] T. W. Lui, M. Bartosiak, G. Piccoli, and V. Sadhya, Online review response strategy and its effects on competitive performance, Tourism Management, vol. 67, pp. 180-190, 2018.

[36] Y. F. Ma, Z. Xiang, Q. Z. Du, and W. G. Fan, Effects of user-provided photos on hotel review helpfulness: An analytical approach with deep leaning, International Journal of Hospitality Management, vol. 71, pp. 120-131, 2018.

[37] R. C. Mayer, J. H. Davis and F. D. Schoorman, An integrative model of organizational trust, Academy of Management Review, vol. 20, no. 3, pp. 709-734, 1995.

[38] D. Mayzlin, Y. Dover and J. A. Chevalier, Promotional reviews: An empirical investigation of online review manipulation, American Economic Review, vol. 104, no. 8, pp. 2411-2455, 2014.

[39] D. Park, J. Lee and I. Han, The Effect of On-Line Consumer Reviews on Consumer Purchasing Intention: The Moderating Role of Involvement, International Journal of Electronic Commerce, vol. 11, no. 4, pp. 125-148, 2007.

[40] D. H. Park, J. Lee and I. Han, The effect of on-line consumer reviews on consumer purchasing intention: The moderating role of involvement, International Journal of Electronic Commerce, vol. 11, no. 4, pp. 125-148, 2007.

[41] P. A. Pavlou and D. Gefen, Building effective online marketplaces with institution-based trust, Information Systems Research, vol. 15, no. 1, pp. 37-59, 2004.

[42] P. A. Pavlou and A. Dimoka, The nature and role of feedback text comments in online marketplaces: implications for trust building, price premiums, and seller differentiation, Information Systems Research, vol. 17, no. 4, pp. $392-414,2006$

[43] C. W. Phang, C. H. Tan, J. Sutanto, F. Magagna, and X. H. Lu, Leveraging O2O commerce for product promotion: An empirical investigation in Mainland China, leee Transactions on Engineering Management, vol. 61, no. 4, pp. 623-632, 2014.

[44] P. Phillips, K. Zigan, S. J. Barnes, and R. Schegg, Understanding the Impact of online reviews on hotel performance: An Empirical Analysis, Journal of Travel Research, vol. 56, no. 2, pp. 235-249, 2016.

[45] P. Racherla, M. Mandviwalla and D. J. Connolly, Factors affecting consumers' trust in online product reviews, Journal of Consumer Behaviour, vol. 11, no. 2, pp. 94-104, 2012.

[46] A. Rampell. (2010) Why online2offline commerce is a trillion dollar opportunity. Techcrunch. [Online]. Available: http://techcrunch.com/2010/08/07/why-online2offline-commerce-is-a-trillion-dollaropportunity/

[47] K. J. Stewart, Trust transfer on the world wide web, Organization Science, vol. 14, no. 1, pp. 5-17, 2003.

[48] T.S.Tseng, Practical field observations on cross border e-commerce startup, Journal of International Business and Economics, vol. 7, no. 2, pp. 136-139, 2019.

[49] T.-M. Tsai, W.-N. Wang, Y.-T. Lin, and S.-C. Choub, An O2O commerce service framework and its effectiveness analysis with application to proximity commerce, Procedia Manufacturing, vol. 3, pp. 3498-3505, 2015.

[50] N. Wang, X.-L. Shen and Y. Sun, Transition of electronic word-of-mouth services from web to mobile context: A trust transfer perspective, Decision Support Systems, vol. 54, no. 3, pp. 1394-1403, 2013.

[51] D. Weathers, S. Sharma and S. L. Wood, Effects of online communication practices on consumer perceptions of performance uncertainty for search and experience goods, Journal of Retailing, vol. 83, no. 4, pp. 393-401, 2007.

[52] R. K. Wilson and C. C. Eckel, Judging a book by its cover: Beauty and expectations in the trust game, Political Research Quarterly, vol. 59, no. 2, pp. 189-202, 2006.

[53] C. Wu, H. Che, T. Y. Chan, and X. Lu, The economic value of online reviews, Marketing Science, vol. 34, no. 5, pp. 739-754, 2015.

[54] L. Xiao, B. Fu and W. Liu, Understanding consumer repurchase intention on O2O platforms: An integrated model of network externalities and trust transfer theory, Service Business, vol. 12, no.4, pp. 731-756, 2018.

[55] L. Yan and X. Wang, Why posters contribute different content in their positive online reviews: A social informationprocessing perspective, Computers in Human Behavior, vol. 82, pp. 199-216, 2018.

[56] J. Yang, R. Sarathy and J. K. Lee, The effect of product review balance and volume on online shoppers' risk perception and purchase intention, Decision Support Systems, vol. 89, no.9, pp.66-76, 2016.

[57] Y. Yang, The influential factors of customer experience in $\mathrm{O} 2 \mathrm{O}$ e-commerce: A quantitative study of what affects Chinese customers' experience in online travel industry under the $\mathrm{O} 2 \mathrm{O}$ e-commerce context, M.S. thesis, Linnaeus University, Växjö, Sweden, 2017.

[58] Q. Ye, R. Law, B. Gu, and W. Chen, The influence of user-generated content on traveler behavior: An empirical investigation on the effects of e-word-of-mouth to hotel online bookings, Computers in Human Behavior, vol. 27 , no. 2, pp. 634-639, 2011

[59] K. Z. K. Zhang, S. J. Zhao, C. M. K. Cheung, and M. K. O. Lee, Examining the influence of online reviews on consumers' decision-making: A heuristic-systematic model, Decision Support Systems, vol. 67, pp. 78-89, 2014.

[60] Y. Zhang, J. Bian and W. Zhu, Trust fraud: A crucial challenge for China's e-commerce market, Electronic Commerce Research and Applications, vol. 12, no.5, pp.299-308, 2013

[61] Y. Zhang, X. G. Chen, X. H. Liu, and N. Zhu, Exploring trust transfer between internet enterprises and their affiliated internet-only banks: An adoption study of internet-only banks in China, Chinese Management Studies, vol. 12, no. 1, pp. 56-78, 2018.

[62] T. Zhou, Y. B. Lu and B. Wang, Examining online consumers' initial trust building from an elaboration likelihood model perspective, Information Systems Frontiers, vol. 18, no. 2, pp. 265-275, 2016. 


\section{Appendix 1: Scale Items and Loadings for Constructs}

\begin{tabular}{|c|c|}
\hline Construct with measurement items & $\begin{array}{c}\text { Factor } \\
\text { loadings }\end{array}$ \\
\hline $\begin{array}{l}\text { Perceived effectiveness of product reviews } \\
\text { 1. I believe that the online reviews are reliable and dependable for customers to judge the } \\
\text { merchant's reputation. } \\
\text { 2. I believe that the online reviews provide accurate information about the merchant's } \\
\text { reputation. } \\
\text { 3. I believe that the online reviews provide relevant feedback information about the } \\
\text { merchant's reputation. } \\
\text { 4. I believe that the online reviews are effective for me to know about this merchant. }\end{array}$ & $\begin{array}{l}0.80 \\
0.89 \\
0.88 \\
0.82\end{array}$ \\
\hline $\begin{array}{l}\text { Perceived effectiveness of numerical ratings } \\
\text { 1. I feel confident that the results of the feedback ratings (positive rating, medium rating, } \\
\text { negative rating) are scientific and effective, which can help me evaluate the merchant. } \\
\text { 2. I feel confident that the feedback ratings provide accurate assessment about this } \\
\text { merchant's reputation. } \\
\text { 3. I believe that the feedback ratings are reliable and dependable to help me evaluate this } \\
\text { merchant. }\end{array}$ & $\begin{array}{l}0.87 \\
0.93 \\
0.90\end{array}$ \\
\hline $\begin{array}{l}\text { Perceived effectiveness of online product descriptions } \\
\text { 1. The online photos/videos provided by the offline merchant are all taken from the actual } \\
\text { physical store. } \\
\text { 2. The online merchant-posted text descriptions about the merchant's products or services } \\
\text { are concrete and reliable. } \\
\text { 3. The online texts /videos/photos provided by the offline merchant update in a timely } \\
\text { manner. } \\
\text { 4. The online texts/videos/photos provided by the offline merchant help me learn about the } \\
\text { merchant's products or services. }\end{array}$ & $\begin{array}{l}0.82 \\
0.88 \\
0.91 \\
0.82\end{array}$ \\
\hline $\begin{array}{l}\text { Trust in platforms } \\
\text { 1. This website is reliable. } \\
\text { 2. This website is competitive comparing with other } \mathrm{O} 2 \mathrm{O} \text { platforms. } \\
\text { 3. This website gives me the impression that it keeps promises and commitments. }\end{array}$ & $\begin{array}{l}0.91 \\
0.88 \\
0.89\end{array}$ \\
\hline $\begin{array}{l}\text { Trust in merchants } \\
\text { 1. The offline merchant is trustworthy. } \\
\text { 2. The offline merchant is capable of providing its products/services. } \\
\text { 3. The offline merchant keeps its promises and commitments. } \\
\text { 4. The offline merchant has my needs in mind. }\end{array}$ & $\begin{array}{l}0.83 \\
0.85 \\
0.85 \\
0.84\end{array}$ \\
\hline $\begin{array}{l}\text { Purchase Intension } \\
\text { 1. When I browse this website, I intend to purchase the merchant's product/service. } \\
\text { 2. I believe it is worthwhile to purchase the merchant's products/services. } \\
\text { 3. I will recommend this merchant to other persons. } \\
\text { 4. Given the chance, I predict I would consider experiencing the merchant's } \\
\text { product/service in the near future. }\end{array}$ & $\begin{array}{l}0.87 \\
0.89 \\
0.88 \\
0.89\end{array}$ \\
\hline
\end{tabular}

